\title{
The Allylamine Grafting on the Plasma Pre-treated Polyester Nonwoven Fabric: Preparation, Characterization and Utilization
}

\author{
Aleš Mráček*, Marián Lehocký ${ }^{1}$, Petr Šmolka, Ondřej Grulich, and Vladimír Velebný ${ }^{2}$
}

\begin{abstract}
This article describes the novel possibility of the polyester (polyethylene terephthalate) surface modification by plasma treatment. Moreover, this modified polyester could be component for the composite material (with hyaluronic acid) used in the wound healing. In this study, the experimental methods: FT-IR spectroscopy, the contact angle measurement, Xray photoelectron spectroscopy and scanning electron microscopy were used for the surface modified polyester characterisation.
\end{abstract}

Keywords: Polyester, Allylamine, Surface modification, Synthetic biomaterials, Biomedical applications, Scaffolds, FT-IR, XPS, SEM, Contact angle measurement

\section{Introduction}

The polyester (PET) nonwoven fabrics have wide spectra of possible applications due to their excellent chemical and mechanical properties compare to other synthetic polymers [1]. Presently, the polyester fibers and nonwoven fabrics, as synthetic biomaterials, are used for many medical (stents) [2,3], molecular biology applications or tissue engineering (scaffolds) [2,4,5]. Often, the surface modifications of PET are necessary for further utilisation. Therefore, the plasma pre-treatment and finishing of PET becomes more and more popular as possibility of surface modification [6,79]. The plasma treatment modifications of the PET surfaces are frequent in order to improving wettability [10] or water- repellent improvement [11]. Consequently, the treatment goals are very often functional water compatible group binding, such as $-\mathrm{COOH},-\mathrm{OH}$, $\mathrm{NH}_{2}$ [7-9,12-21], or $\mathrm{TiO}_{2} / \mathrm{MoO}_{3}$ [22]. Moreover, the amine $\left(-\mathrm{NH}_{2}\right)$ groups are very important for chemical reactions with proteins or surface interactions with cells [1]. The synthetic biomaterials, such as poly(tetrafluoroethylene), modified by $\mathrm{NH}_{2}$ were used for peptide immobilization [23]. Some surface modifications experiments are only focused on the plasma surface modification without following physical-chemical treatment and these plasma pretreated surfaces are directly used for biochemical reaction (PEGylation) [1], molecular biology application [24,25] or biosensors (thin metal layers on PET [26]).

This paper is focused to the plasma treatment and following novel surface modification of polyester for further biomedical applications.

\section{Experimental}

Materials

The polyester (nonwoven fabric of polyethylene terephthalatePET, the area density: $\mathrm{s}_{\mathrm{m}}=140 \mathrm{~g}-\mathrm{m}^{\circ}$ ) was obtained from Inotex, Ltd. This polyester was pre-treated in plasma with processing gasses: argon (Linde Gas, a.s., purity number 3.1.) and nitrogen (Linde Gas, a.s., purity number 3.1.). The modified samples of polyester were exposed $(24 \mathrm{~h})$ in allylamine $\left(\mathrm{H}_{2} \mathrm{C}=\mathrm{CH}-\mathrm{CH}_{2}-\mathrm{NH}_{2}\right.$, standard purity $99,5 \%$, Sigma Aldrich) after pre-treatment in the plasma. The pretreated samples were by (1 min left) on ambient air after plasma treatment and before allyamine vapour deposition. The n-heptan (viscosity: $r j\left(20{ }^{\circ} \mathrm{C}\right)=0,409 \mathrm{mPa}-\mathrm{s}$, density: $p$ $\left(20^{\circ} \mathrm{C}\right)=684 \mathrm{~kg}^{*} \mathrm{~m}^{\prime 3}$ and surface energy: $a\left(20{ }^{\circ} \mathrm{C}\right)=20,4 \mathrm{mN}-\mathrm{m}^{\prime 1}$, Sigma Aldrich) and de-ionized water (viscosity: $77\left(20^{\circ} \mathrm{C}\right)=$ 1, $002 \mathrm{mPa}$-s, density: $p\left(20^{\circ} \mathrm{C}\right)=998 \mathrm{~kg}-\mathrm{m}^{13}$ and surface energy: $\left.\measuredangle\left(20^{\circ} \mathrm{C}\right)=72,8 \mathrm{mN}-\mathrm{m}^{\text {“1 }}\right)$ were used for the contact angle measurement.

\section{Polyester Modification Processing}

The PET samples were pre-treated in the low-temperature pulsed DC discharge plasma at $40 \mathrm{kHz}$ (Plasma system "FEMTO", Diener electronic $\mathrm{GmbH}+\mathrm{Co} . \mathrm{KG}$ ). The processing gases were used argon and nitrogen. The time of plasma treatment $300 \mathrm{~s}$, the generator power $100 \mathrm{~W}$ and processing gasses flow $90 \mathrm{~cm}^{3}-\mathrm{min}^{1}$ were the processing conditions. The pre-treated PET samples were exposed for $24 \mathrm{~h}$ in the allylamine vapour (abbreviation of samples: PETAr-allylamine and PET- $\mathrm{N}_{2}$-allylamine). The hypothesis of allylamine bonding to plasma pre-treatment monomer of PET can be seen in Figure 1 (this hypothesis is deeper discussed by means of XPS measurement in 3rd section Results and discussion). 


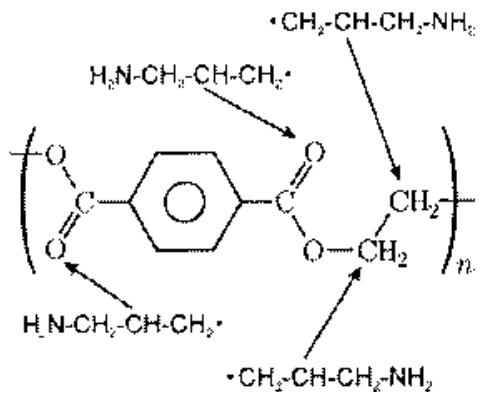

Figure 1. The presumed reaction of the allylamine bonding to PET monomer.

\section{Apparatus and Methods}

The infrared spectra were taken using Shimadzu FTÏR- 8201 (ATR method with SeZn crystal). The spectral resolution of the instrument was $4 \mathrm{~cm}^{\text {“1 }}$ in all spectra determinations.

Washburn method [27] in a modification proposed by the Kriiss company for the apparatus Krüss K12 Tensiometer was used to determine water contact angle for virgin and plasma-modified PET. The material was in the form of a non-woven fabric. This approach is based on observing penetration of the liquid into the porous structure of polymeric material. Firstly, so called capillary constant has to be determined with a liquid where zero the contact angle with the solid is expected. The capillary constant value $c$ $(2,32 \pm 0,09) \mathrm{TO}^{\prime \prime} \mathrm{cm}^{5}$ was determined for $\mathrm{n}$-heptane. Then, the measurement with desired liquid is performed and previously acquired capillary constant is used for characterization of the solid material structure. The dependence of the liquid mass square versus time is observed as

$$
m^{2}=\frac{\cos \theta \cdot \rho^{2} \cdot \sigma \cdot c}{\eta} \cdot t
$$

where $m$ is the mass of liquid penetrating into the material, $r j$ means the dynamic viscosity of the liquid, $p$ denotes the density of the liquid, cr signifies the surface free tension of the liquid, $c$ corresponds to the capillary constant and $<9$ is the contact angle between the testing liquid and tested solid material. The contact angle measurement was performed with a holder supplied by Kriiss for the Sorption method. Circles with a diameter $12 \mathrm{~mm}$ were cut out from the tested PET nonwoven fabrics and placed inside the holder. Three values of the contact angle were averaged to obtain one representative value.

The XPS analysis of PET fibers was carried out with spectrometer (EA 125, DAR 400, Omicron) at an X-ray energy of $1253.6 \mathrm{eV}\left(\mathrm{Mg} K_{a}\right)$ in the constant pass energy mode $(15 \mathrm{eV})$. The operational pressure was approximately $10^{16} \mathrm{~Pa}$. The binding energy of $\mathrm{N}^{\mathrm{ls}}$ can be seen in Figure 2.

The morphologies of the untreated and treated PET fibers were observed by scanning electron microscopy (TESCAN VEGA/LMU).

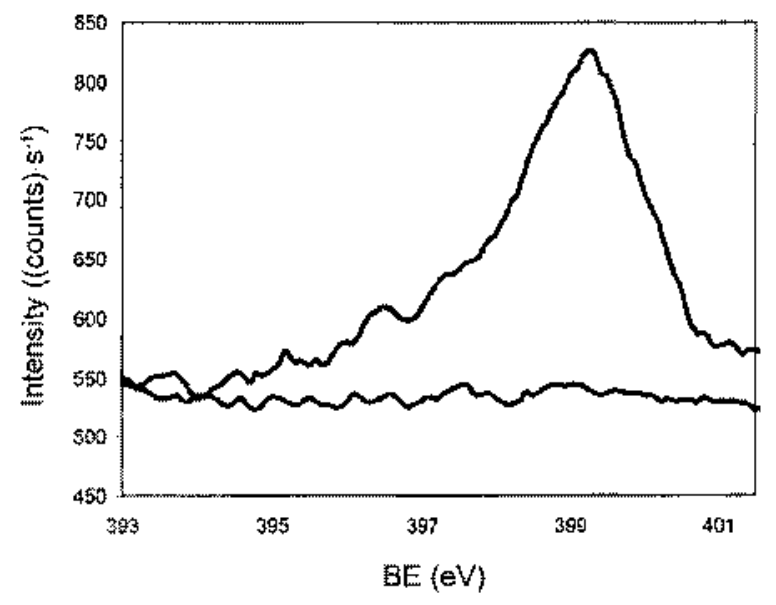

Figure 2. The binding energy ofNls.

\section{Results and Discussion}

The infrared spectrum of allylamine (Figure 3) shows the characteristic stretching vibration of amine (asymmetric $3373 \mathrm{~cm}^{\text {“1 }}$ and symmetric $3294 \mathrm{~cm}^{\text {"1 }}$ ) and the vibration $3200 \mathrm{~cm}^{\prime 1}$ is the overtone of $\mathrm{NH}_{2}$ bending vibration at $1650 \mathrm{~cm}^{\text {“1 }}$. The vibration at $3080 \mathrm{~cm}^{11}$ corresponds to the hydrogen asymmetric stretching of $\mathrm{CH}=\mathrm{CH}_{2}$. The stretching vibration of $\mathrm{C}-\mathrm{H}$ can be seen at 2980, 2916 , and $2854 \mathrm{~cm}^{\prime 1}$. The bending vibration of amine corresponds to $1650 \mathrm{~cm}^{\prime 1}$ and overlaps the weak vibration of $\mathrm{C}=\mathrm{C}$ stretching. The vibration at $1420 \mathrm{~cm}^{\prime 1}$ is $\mathrm{C}-\mathrm{H}$ bending. The peaks at 997, 914, and $825 \mathrm{~cm}^{\prime 1}$ can be assigned to the "out of plane" hydrogen wagging [28].

The spectrum of pure polyester fibers can be seen in Figure 4(a). The absorption at $3420 \mathrm{~cm}^{\text {"1 } 1}$ is overtone of stretching vibration $(\mathrm{C}=0)$ at $1710 \mathrm{~cm}^{\prime 1}$ for the ester group. The stretching vibration (C$\mathrm{H})$ of benzene ring occurs at $3030 \mathrm{~cm}^{\prime 1}$. The saturated aliphatic hydrocarbon occurs at 2954 and $2916 \mathrm{~cm}^{\prime 1}$ as the asymmetric and symmetric stretching vibration of $\mathrm{C}-\mathrm{H}$. The strong carbonyl absorption can be

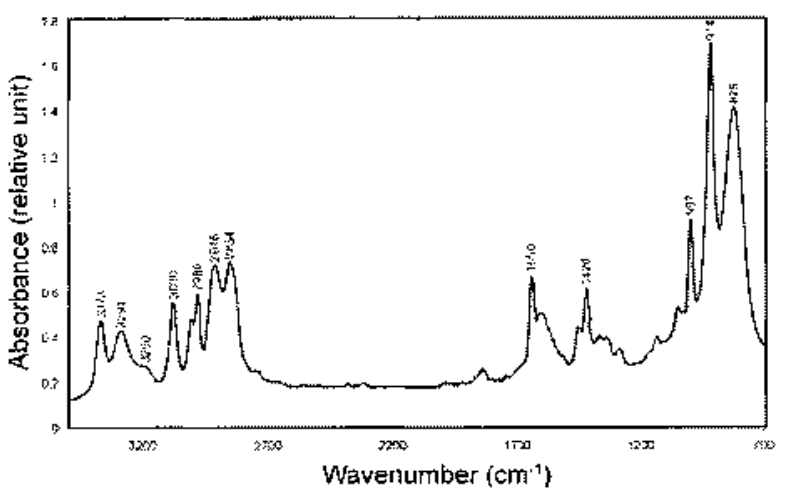

Figure 3. The infrared spectrum of allylamine. 
seen at $1710 \mathrm{~cm}^{-1}$. The absorption at 1547 and $1516 \mathrm{~cm}^{\prime 1}$ is $\mathrm{C}-\mathrm{H}$ bending vibration of benzene ring. The bending vibration (H-C-H) of the ethylene group occurs at $1462 \mathrm{~cm}^{-1}$. The absorption at 1350 $\mathrm{cm}^{\prime 1}$ is wagging $(\mathrm{C}-\mathrm{H})$ for ethylene glycol. Likewise, the absorptions at $1240 \mathrm{~cm}^{\prime 1}$ and at $1090 \mathrm{~cm}^{\prime 1}$ correspond with the asymmetric stretching vibration of $\mathrm{C}-\mathrm{O}-\mathrm{C}$ and the stretching vibration of $\mathrm{O}-\mathrm{C}$. The absorption at $1014 \mathrm{~cm}^{11}$ is bending $\mathrm{C}-\mathrm{H}$ vibration in plane and the absorption at $720 \mathrm{~cm}^{\prime 1}$ is rocking vibration of $\mathrm{CH}_{2}$. The PET-

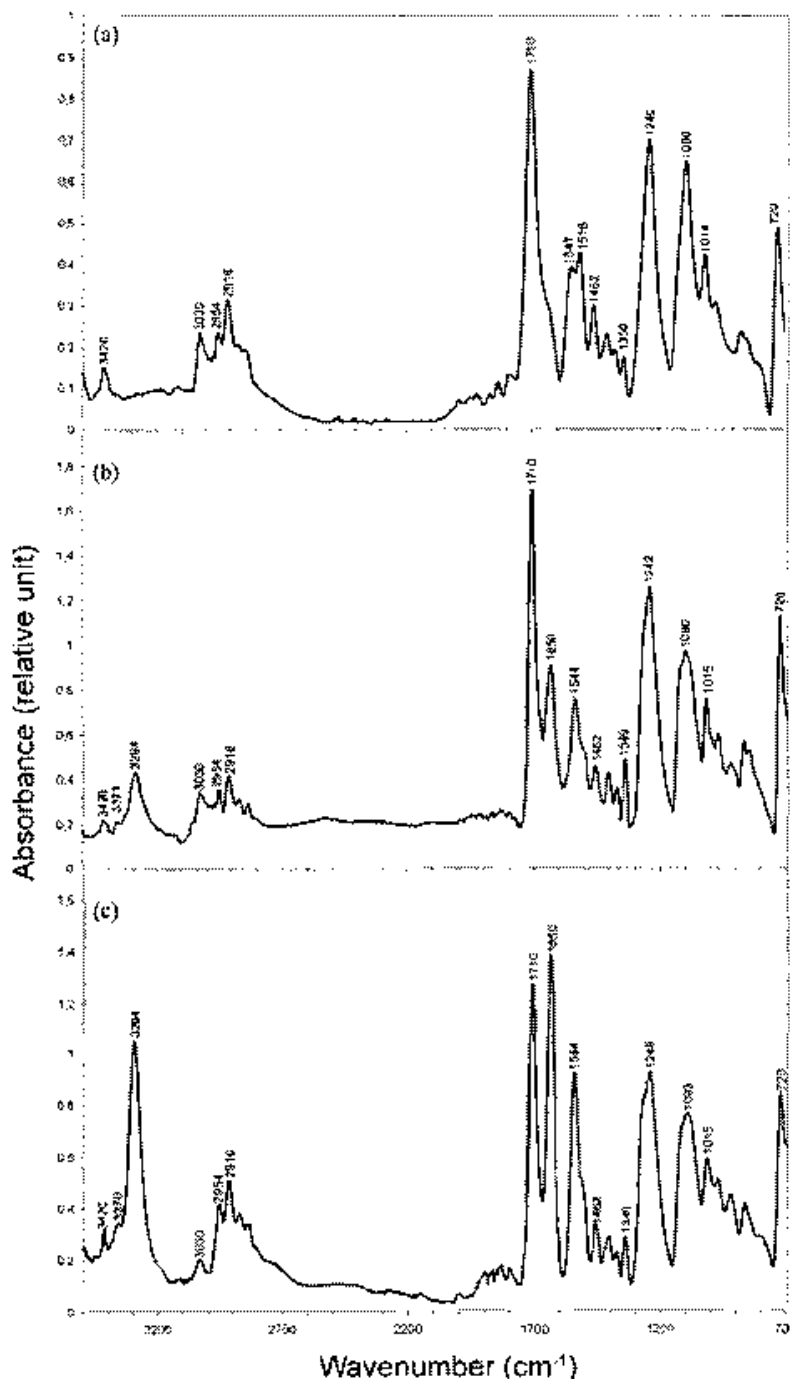

Figure 4. The infrared spectra of polyesters; (a) the pure polyester, (b) PET-Ar-allylamine, and (c) PET- $\mathrm{N}_{2}$-allylamine.
Ar-Allylamine and PET- $\mathrm{N}_{2}$-Allylamine samples are shown in Figures 4(b) and 4(c). The absorptions at $3373 \mathrm{~cm}^{\prime \prime}$ and at 3294 $\mathrm{cm}^{\prime 1}$ are asymmetric and symmetric stretching vibration for amine group and the absorption at $1650 \mathrm{~cm}^{\prime 1}$ is $\mathrm{NH}_{2}$ bending vibration [28]. These infrared spectra can be interpreted as an achievement of the allylamine chemical bonding on the surface of PET fibers.

The contact angle values of deionised water at various samples are summarised in Table 1. The insignificant difference of values for the water contact angle can be observed on argon or nitrogen plasma-treated sample compared to the virgin sample. Significantly higher water contact angle value was observed for the plasmatreated sample followed by allylamine grafting. The chemical nature of the allylamine non-polar carbohydrate chain plays important role in this case. Moreover, the SEM images show relatively strong wrinkling of fibres surface which leads to the contact angle value increase.

The surface composition of the pure and modified PET obtained from XPS is summarized in Table 2. As can be seen, the percentage representation of analyzed elements $(\mathrm{C}$,

$\mathrm{O}, \mathrm{N}$ ) is different in both modified samples of PET. The amount of nitrogen is increasing for the sample PET-Ar- Allylamine while the content of carbon is decreasing (see pure sample in Table 2). On the other hand, the nitrogen percentage is increasing for sample PET$\mathrm{N}_{2}$-Allylamine in connection with the decrease of oxygen content. The assumption of allylamine bonding in two possibilities (Figure 1) can be voiced due to this percentage differences: (a) the allylamine was grafted via carbon in case argon plasma pretreatment, (b) the allylamine was incorporated via carbonyl oxygen from carboxylic group in case of the nitrogen plasma pretreatment. Thus, these results are in agreement with FT-IR results if allows for the proportions of peaks for $\mathrm{NH}_{2}$ to $\mathrm{C}-\mathrm{O}-\mathrm{C}$ or $\mathrm{C}=0$.

The surface morphology changes between virgin and treated polyester fibers can be seen in the Figure 5. The obvious difference between untreated polyester (Figure 5(a)) and pre-treated polyester by the $\mathrm{Ar}$ or $\mathrm{N}_{2}$ plasma (Figure 5(b) or 5(c)) is observable on the sample surfaces. The

Table 2. The surface composition of the pure and modified PET (in percentage)

\begin{tabular}{cccc}
\hline Sample & Cls & 01s & N1s \\
\hline Pure PES & $84,6 \pm 2,5$ & $15,4 \pm 0,3$ & 0 \\
PES-Ar-allylaminc & $78,1 \pm 1,8$ & $16,5 \pm 0,6$ & $5,4 \pm 0,05$ \\
PES-N2-allylamine & $84,3 \pm 2,1$ & $10,8+0,4$ & $5=0,1$ \\
\hline
\end{tabular}

Table 1 . The water contact angles with standard deviation

\begin{tabular}{cccccc}
\hline Sample & Pure PES & PES-N ${ }_{2}$ Plasma & PES-Ar plasma & PFS-AT-Allylamine & PES-N $-A l l y l a m i n e$ \\
\hline $\begin{array}{c}\text { Contact angle } \\
\text { (degrees) }\end{array}$ & $66 \pm 2$ & $65 \pm 3$ & $66 \pm 1$ & $87 \pm 1$ & $85 \pm 2$ \\
\hline
\end{tabular}



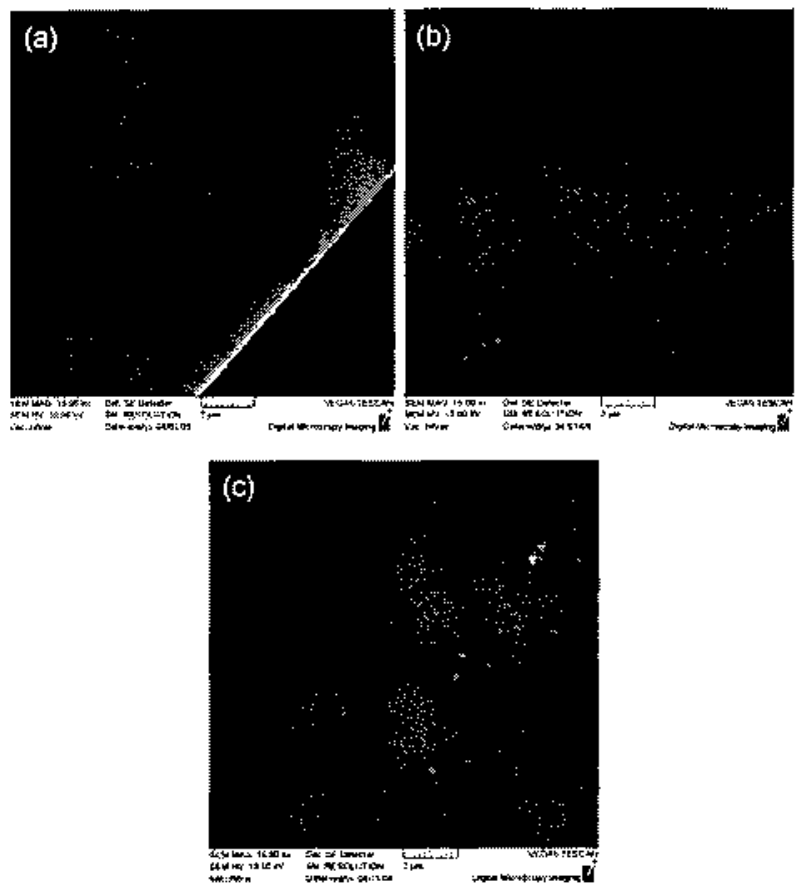

Figure 5. The SEM images of PET fibers; (a) untreated PET, (b) PET-Ar plasma, and (c) PET- $\mathrm{N}_{2}$ plasma.

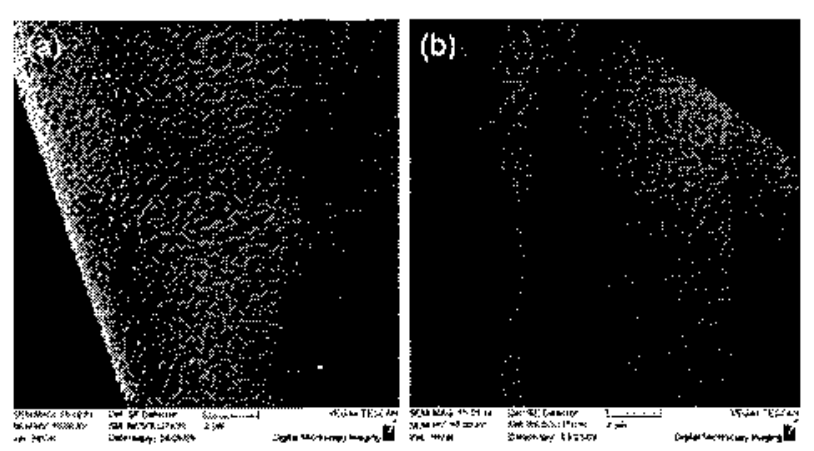

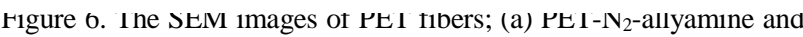
(b) PET-Ar-allylamine.

plasma $\left(\mathrm{Ar}\right.$ or $\mathrm{N}_{2}$ ) pre-treated polyesters exposed in allylamine (Figure 6(a) and 6(b)) have relatively wrinkled surface in comparison to the pure PET fibers. On the other hand, some wrinkling of surface can be seen in pre-treated samples only (Figure $5(\mathrm{~b})$ or 5(c)) which is in agreement with publication by Krump et al. [29].

\section{Conclusion}

In this research, PET fibres are plasma pre-treated and consequently grafted by allyamine. The presented results obtained from FT-IR and XPS measurements validate this possibility. Through XPS analysis, it is shown that the argon plasma pre-treatment lead to grafting via carbon and nitrogen plasma pre-treatment via oxygen. However, this assumption should be deeper explored by other methods (such as Tg-glass transition temperature measured by DSC or DTA method, neither EPR could show-up some radicals decay). These studies will be submitted by authors as results in next publications. The SEM images can explain increasing contact angle for both modified samples, because the surfaces after treatment are very furrowed.

\section{Acknowledgements}

This research was supported by grant of the Czech Ministry of Education (MSMT Czech Republic, VZ MSM 7088352101), by the Czech Science Foundation, GACR (project 104/09/H080), by the internal grant of TBU in Zlin No. IGA/26/FT/10/D funded from the resources of specific university research and by grant of company CPN, Ltd.

\section{References}

1. P. K. Chu, J. Y. Chen, L. P. Wang, and N. Huang, Mater Set Eng, R 36, 14 (2002).

2. S. Ramakrishna, J. Mayer, E. Wintermantel, and W. Leong Kam, Compos. Set Technol., 61, 1189 (2001).

3. P. M. Galletti and P. Aebischer, Surgery, 103, 231 (1988).

4. T. J. Yu and C. C. Chu, J. Biomed. Mater Res., 27, 1329 (1993)

5. T. J. Yu, D. M. Ho, and C. C. Chu, J. Invest. Surg., 7, 195 (1994)

6. R. Shishoo, "Plasma Technologies for Textiles", Woodhead Publishing Ltd., Cambridge, 2007.

7. A. Vesel, M. Mozetic, and A. Zalar, Surf. Interf Anal., 40, 661 (2008).

8. A. Vesel, M. Mozetic, and A. Zalar, Vacuum, 82, 248 (2007)

9. I. Denysenko, K. Ostrikov, U. Cvelbar, M. Mozetic, and N. A. Azarenkov, J. Appl. Phys., 104, 073301 (2008).

10. C. W. Kan and C. W. M. Yuen, Nucl. Instrum. Meth. Phys. Res. B, 266, 127 (2008).

11. Y. Y. Ji, H. K. Chang, Y. C. Hong, and S. H. Lee, Current Appl. Phys., 9, 253 (2009).

12. R. Morent, N. De Geyter, J. Verschuren, K. De Clerck, P. Kiekens, and C. Leys, Surf. Coat. Technol., 202, 3427 (2008)

13. N. De Geyter, R. Morent, C. Leys, L. Gengembre, and E. Payen, Surf Coat. Technol, 201, 7066 (2007).

14. N. De Geyter, R. Morent, and C. Leys, Surf. Coat. Technol, 201, 2460 (2006).

15. A. Vesel, I. Junkar, U. Cvelbar, J. Kovac, and M. Mozetic, Surf. Interf. Anal., 40, 1444 (2008).

16. A. Vesel and M. Mozetic, J. Phys.: Conference Series, 100,012027 (2008).

17. M. M. Hossain, J. Miissig, A. S. Herrmann, and D. 
Hegemann, J. Appl. Polym. Sci., Ill, 2545 (2009).

18. M. Kostopoulou, E. Amanatides, and D. Mataras, Journal of Optoelectronics and Advanced Materials, 10, 2043 (2008).

19. Y. Shin, K. Son, and D. I. Yoo, J. Appl Polym. Sci., 103, 3655 (2007).

20. N. A. Tabaliov and D. M. Svirachev, Appl. Surf. Sci., 253, 4242 (2007).

21. S. Liu and G. Sun, Polymer, 49, 5225 (2008).

22. H. Matsui, S. Nagano, S. Karruppuchamy, and M. Yoshhara, Current Applied Physics D01:10.1016/j.cap. 2008.05.007 (in press).

23. C. Baquey, F. Palumbo, M. C. Porte-Durrieu, G. Legeay, A. Tressaud, and R. d'Agostino, Nucl. Instrum. Meth.
Phys. Res. B, 151, 255 (1999).

24. G. H. Ryu, W. S. Yang, H. W. Roh, I. S. Lee, J. K. Kim, G. H. Lee, D. H. Lee, B. J. Park, M. S. Lee, and J. C. Park, Surf. Coat. Technol., 193, 60 (2005).

25. Y. Wan, C. Tu, J. Yang, J. Bei, and S. Wang, Biomaterials, 27, 2699 (2006).

26. A. Mackova, V. Svorcik, P. Sajdl, S. Stryhal, J. Pavlik, P. Malinsky, and M. Slouf, Vacuum, 82, 307 (2008).

27. E. W. Wasbum, Phys. Rev., 17, 273 (1921).

28. D. W. Mayo, F. A. Miller, and R. W. Hannah, "Course Notes on the Interpretation of Infrared and Raman Spectra", John Wiley \& Sons, Inc., New Jersey, 2003.

29. H. Krump, I. Hudec, and A. S. Luyt, Int. J. Adhes. Adhes., 25, 269 (2005). 